\title{
Enhanced Temperature Sensitivity of Thermally Regenerated Direct Ultraviolet Written Gratings in Germanium Doped Core Fiber
}

\author{
Alexander Jantzen', Rex H. S. Bannerman', Lewis J. Boyd ${ }^{2}$, Peter G. R. Smith ${ }^{1}$, Christopher Holmes ${ }^{1}$ \\ 1. University of Southampton, University Road, SO17 2LH, Southampton, United Kingdom \\ 2. Parker Hannifin Aerospace, 2510 The Quadrant, BS32 4AQ, Bristol, United Kingdom
}

The use of thermally regenerated gratings for monitoring harsh environments is becoming increasingly attractive due to their thermal resilience and high precision. They are a unique type of Bragg grating created through annealing UV-laser written Fiber Bragg Gratings (FBGs) at high temperatures (above $600^{\circ} \mathrm{C}$ ) and they have been demonstrated to operate at temperatures over $1000{ }^{\circ} \mathrm{C}$ in oxygen free environments [1]. In this work we report two new observations. Firstly, a second phase thermal regeneration process at temperatures above $650{ }^{\circ} \mathrm{C}$ and secondly an enhanced thermal response for these second phase regenerated gratings of over $140 \%$. Uniquely, fabrication of the gratings was made through a small spot Direct Ultraviolet Writing (DUW) process. This utilizes a high precision four-axis stage system and a frequency double argon-ion continuous wave $244 \mathrm{~nm}$ laser that is split and recombined at a focus to form a $\sim 7 \mathrm{~m}$ diameter interferometric spot [2]. A series of 46 different FBGs, from 1400 to $1620 \mathrm{~nm}$, were written into a single non-hydrogen loaded double clad germanium doped $4 \mu \mathrm{m}$ core fiber (Nufern GF4A). Gratings in the series were written with fluences ranging from $0.05 \mathrm{~kJ} / \mathrm{cm}^{2}$ up to $90 \mathrm{~kJ} / \mathrm{cm}^{2}$.

The written fiber was subsequently heated inside an atmosphere controlled tube furnace and ramped at 5 ${ }^{\circ} \mathrm{C} / \mathrm{min}$ to $1050{ }^{\circ} \mathrm{C}$ with a pure oxygen flow of $2 \mathrm{~L} / \mathrm{min}$. During the ramp, a broadband SLED source was used in conjunction with a data logging optical spectrum analyzer to monitor the spectral reflection response of the fiber and gratings in real time. A spectrum from 1400 to $1620 \mathrm{~nm}$ was recorded at every $2{ }^{\circ} \mathrm{C}$ temperature increase and stored. for subsequent data analysis.
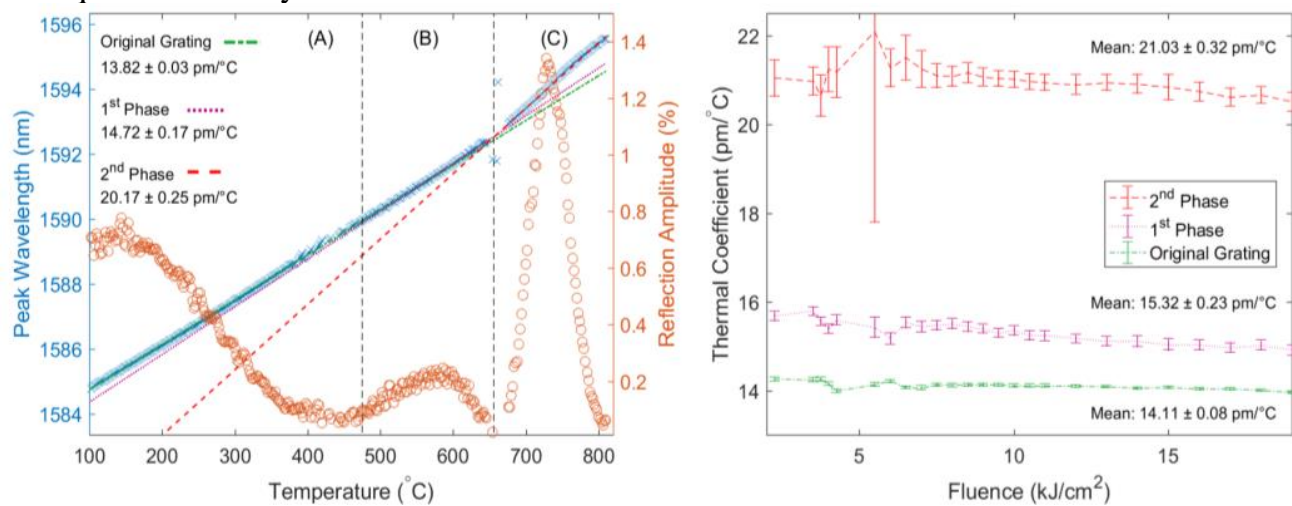

Fig. 1 (Left) Bragg grating thermal response to a $5^{\circ} \mathrm{C} / \mathrm{min}$ ramp rate with evaluated thermal coefficients for separate regeneration phases A, B and C. (Right) Thermal coefficients of separate regenerations versus their writing fluence.

The mean value and its standard deviation is presented adjacent to the corresponding data.

Three original features of this work are recognized. Firstly is the regeneration shown in Fig. 1 having been achieved in a pure oxygen environment contrary to most reported cases. Second, evidence of a double regeneration can be seen as the reflection intensity between 500 and $650{ }^{\circ} \mathrm{C}$ strengthens prior to the main regeneration peaking at $720^{\circ} \mathrm{C}$. Thirdly, during the second regeneration, a marked shift in the thermal response of the grating can be noted, with an increase from $14.11 \pm 0.08 \mathrm{pm} /{ }^{\circ} \mathrm{C}$ the original gratings to $21.03 \pm 0.32 \mathrm{pm} /{ }^{\circ} \mathrm{C}$. This marked increase in response was observed on all major gratings in the fiber. A slight increase in thermal response is expected with temperature and this can be seen in the $1^{\text {st }}$ regeneration phase, although this effect is insufficient to explain the enhancement of the response in the $2^{\text {nd }}$ phase as an obvious discontinuity can be seen. The authors believe that the double regeneration is related to the double clad structure inside the fiber and the transfer of the Bragg gratings from core to cladding interface.

A demonstration of enhanced thermal sensitivity of DUW FBGs in germanium doped small core fiber has been shown with the largest yet noted increase. This opens up for new optically based higher precision temperature sensors. We will present the latest results on DUW thermally regenerative gratings, details of fabrication, real-time monitoring results and elaborate on the peculiarities of the double regeneration.

\section{References}

[1] Mihailov, S. J., Grobnic, D., Walker, R. B., Hnatovsky, C. A., Ding, H., Coulas, D.., Lu, P., “New technique for fabrication of low loss high temperature stable high reflectivity FBG sensor arrays," Proc. SPIE 9852, Fiber Opt. Sensors Appl. XIII 9852, E. Udd, G. Pickrell, and H. H. Du, Eds., 98520F (2016).

[2] Sima, C., Gates, J. C., Rogers, H. L., Mennea, P. L., Holmes, C., Zervas, M. N.., Smith, P. G. R., "Ultra-wide detuning planar Bragg grating fabrication technique based on direct UV grating writing with electro-optic phase modulation.," Opt. Express 21(13), 1574715754 (2013). 